\title{
Identification of a Cam Clay Model through Shear-Box and Oedometer Tests. Application to Lateritical Soils from Senegal (West Africa)
}

\author{
Cheikhou Ndiaye' ${ }^{1}$ Yves Berthaud ${ }^{2}$ \\ ${ }^{1}$ Laboratoire de Mécanique et Modélisation-UFR Sciences de l'Ingénieur, Université de Thiès, Thiès, Sénégal \\ ${ }^{2}$ Sorbonne Universités, UPMC Université Paris 06, CNRS, Institut Jean le Rond d'Alembert, Paris, France \\ Email: cheikhou.ndiaye@univ-thies.sn
}

How to cite this paper: Ndiaye, C. and Berthaud, Y. (2018) Identification of a Cam Clay Model through Shear-Box and Oedometer Tests. Application to Lateritical Soils from Senegal (West Africa). Geomaterials, 8, 1-13.

https://doi.org/10.4236/gm.2018.81001

Received: May 22, 2017

Accepted: November 26, 2017

Published: November 29, 2017

Copyright (C) 2018 by authors and Scientific Research Publishing Inc. This work is licensed under the Creative Commons Attribution International License (CC BY 4.0).

http://creativecommons.org/licenses/by/4.0/

\begin{abstract}
The main objective of this research is to study the mechanical behaviour of tropical soils using elasto-plastic constitutive equations in the so-called limit and critical states. Indeed, researchers of the Cambridge University had noticed that during their various experiments, the rate of volumetric deformation $\left(\dot{\varepsilon}_{v}\right)$ of the sample tending to zero every time the rupture of the specimen is reached during a test performed on a clay specimen Roscoe et al., 1958. To better understand and clarify this mechanical behaviour, a description has been proposed in the (e, p, q) representation that means void ratio, volumetric stress (spherical pressure) and deviatoric stress. This frame of theoretical study and apprehension is called: the theory of the Critical State. One of the major problems met at the time of our present research is the non-availability of triaxial apparatus allowing us to achieve some tests on tropical soils (samples from Senegal in West Africa) and to describe the behaviour of these materials easily like the researchers of the university of Cambridge in the theory of the critical state. To by-pass this difficulty, we decided to consider two very classical and simple mechanical tests: shear-box and the oedometer test as well as the interrelationship of the results given by the tests and some theoretical calculations. This is a way to identify an elasto-plastic model (the modified Cam Clay model) without any triaxial experiment. Indeed it supposes the model to be suitable to describe the mechanical behaviour of the considered clays.
\end{abstract}

\section{Keywords}

Behaviour, Elasto-plastic, Limit State, Critical State, Volumetric Distortion, Theory, Triaxial, Shearing, Oedometer, Cam Clay 


\section{Introduction}

The concepts of limit and critical states have been established initially by the researchers of the University of Cambridge from both isotropic consolidation and triaxial tests on clays reconstituted in the laboratory [1] [2] [3]. In this present research, we want to apply these concepts to tropical soils (lateritic gravel) while identifying them by the modified Cam Clay model. All the parameters of the Cam Clay model that enable to derive the yield surfaces and the Critical States Lines (CSL) have been recovered from theoretical relations between the experimental response in shear (shear-box) and the cycles of oedometer unloading-reloading. In the last part of the paper we will compare results given by this method to a more classical identification process based on triaxial tests.

\section{Approach and Results}

\subsection{Sampling}

All the samples that we studied here come from Senegal in West Africa "Figure 1". It is about two lateritic careers in two localities: The lateritic career of Sindia and the lateritic career of Keur Samba Kane. The choice of these two careers is justified by the fact that we want to study examples of tropical soils. And those two lateric careers of Sindia and Keur Samba Kane participated in the realization of the biggest works of the country.

The preliminary analyses showed that these clays are low plastic lateritic gravels with the following characteristics "Table 1".

\subsection{Results of the Shearing Tests (Done Using the Shear-Box)}

We used a square shear-box $(60 \mathrm{~mm})$ to make the whole set of tests on our samples. Our samples have all been compacted to the middle energy of Proctor (theoretically) in Proctor moulds as specimen of more or less $70 \mathrm{~mm}$ in height. These specimens were realized in several copies at the same time and then packed in tight films. Before the compaction of our samples in the Proctor moulds, we made them pass to the sifter of the module $44(20 \mathrm{~mm})$ in accordance with the norm French Industrial Standards Authority (AFNOR) to knead to the contents in water of the Proctor modified then found for every sample.

After this modus operandi, we realised the tests in three phases of respective loads, corresponding to initial normal constraints of $196 \mathrm{kPa}, 392 \mathrm{kPa}$ and 784 $\mathrm{kPa}$ with the speed fixed to $0.3 \mathrm{~mm} / \mathrm{min}$ for all the tests. The characteristics of shearing that we have found are summarized in the "Table 2" and on the "Figure 2". "Figure 3" and "Figure 4" are the corresponding figures for the sample of Sindia and the "Table 3" and the "Figure 5", "Figure 6" and "Figure 7" for the sample of Keur Samba Kane.

The lateritic soil of Sindia presents a strong cohesion due to the fact that the effect of compaction cements the sol. The evolution of the tangential stress is monotonic and becomes rather constant when the resistance to the maximal shearing is reached. It is due to the fact that the compactness does not reach $95 \%$ 

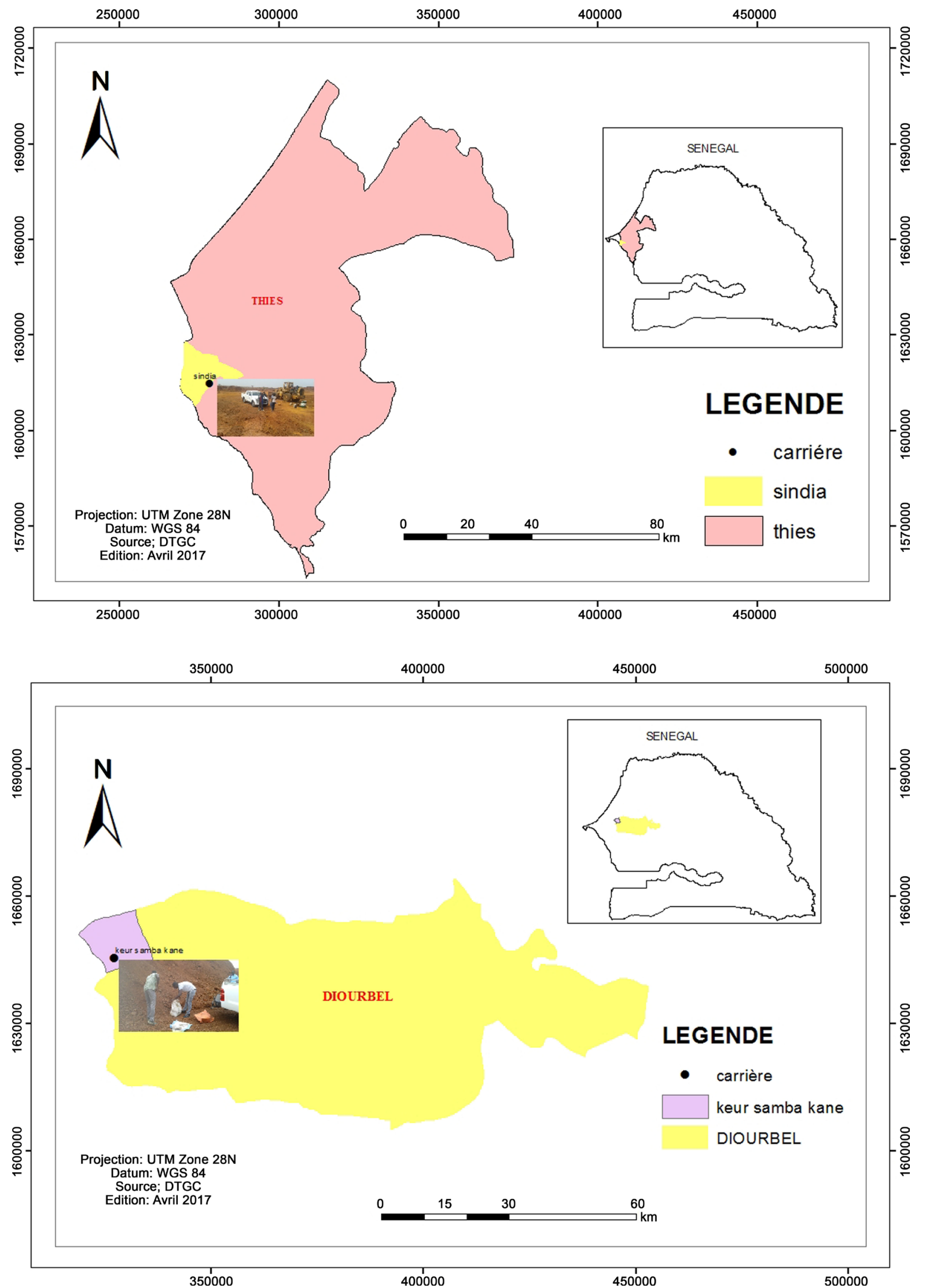

Figure 1. Localization of the lateritic careers studied. 
Table 1. Characteristics of the lateritic gravels studied.

\begin{tabular}{ccc}
\hline Characteristics & Sindia & Keur Samba Kane \\
\hline LL (Liquid Limit) & 30.7 & 31.1 \\
LP (Plastic Limit) & 15.7 & 17.6 \\
IP (Plasticity Index) & 15 & 13.4 \\
CBR (California Ratio) & 56.2 & 79.4 \\
$\gamma_{S}\left(\mathrm{kN} / \mathrm{m}^{3}\right)$ (Specific Density) & 27 & 26 \\
$\gamma_{d \max }\left(\mathrm{kN} / \mathrm{m}^{3}\right)$ (Dry Bulk Density) & 21.1 & 21.4 \\
$W_{O P M}(\%)$ (Opt. Water Content) & 8.2 & 8.2 \\
\hline
\end{tabular}

Table 2. Characteristics of shearing tests-Lateric gravel of Sindia.

\begin{tabular}{cc}
\hline Characteristics & Sindia \\
\hline$C(\mathrm{kPa})$ & 117 \\
$\phi\left(^{\circ}\right)$ & 18 \\
$\gamma_{h}\left(\mathrm{kN} / \mathrm{m}^{3}\right)$ & 21.5 \\
$\gamma_{d}\left(\mathrm{kN} / \mathrm{m}^{3}\right)$ & 17.8 \\
$\omega_{i}(\%)$ & 13.3 \\
$\omega_{f}(\%)$ & 20.9 \\
\hline
\end{tabular}

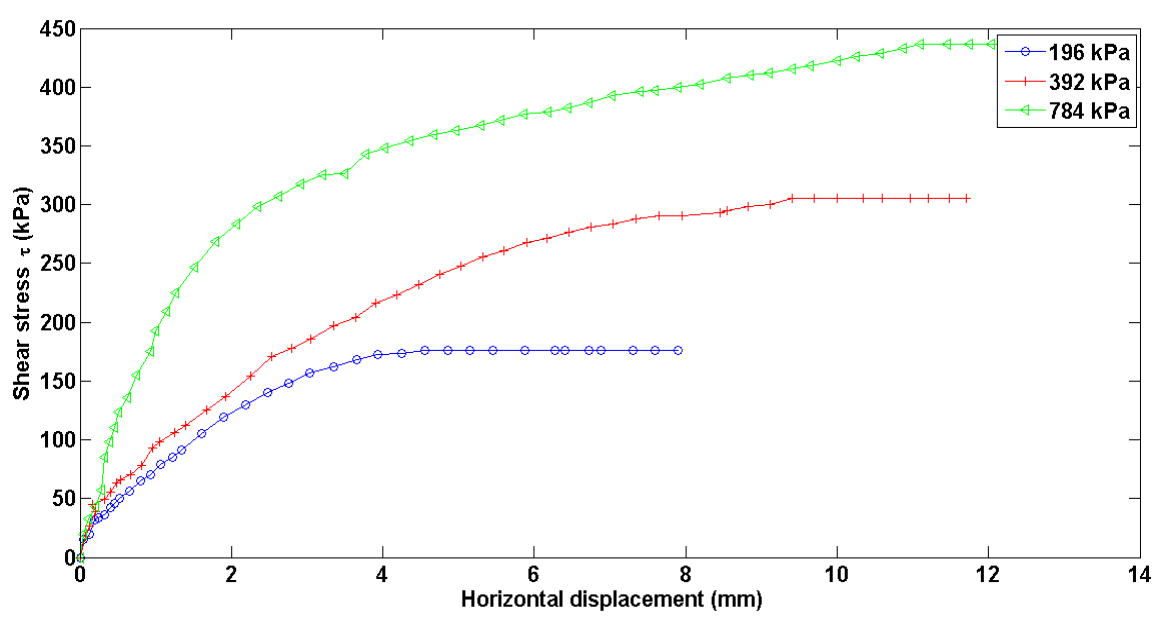

Figure 2. Evolutions of the Shear stress according to the horizontal displacement-Compacted Lateritic gravel of Sindia.

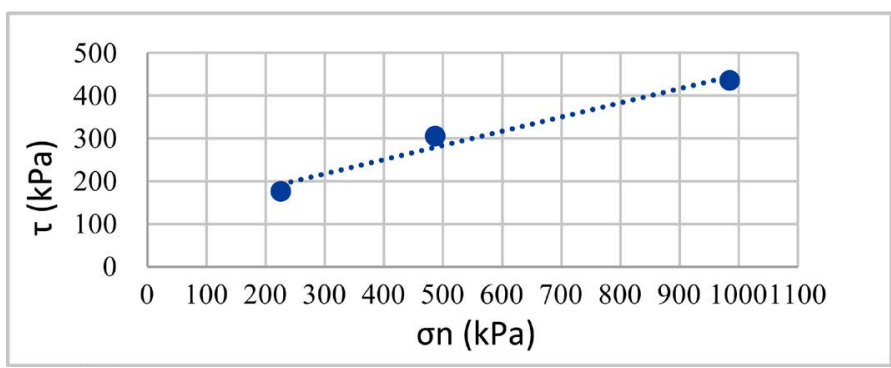

Figure 3. Intrinsic curve of the compacted lateritic gravel of Sindia. 


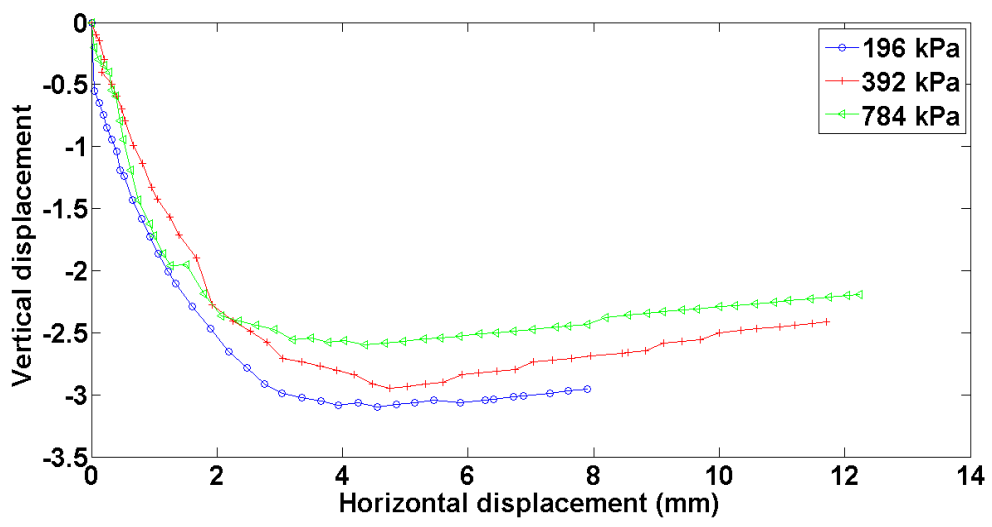

Figure 4. Evolutions of the vertical displacements according to the horizontal displacement-compacted lateritic gravel of Sindia.

Table 3. Characteristics of shearing tests Lateritic gravel of Keur Samba Kane.

\begin{tabular}{cc}
\hline Characteristics & Keur Samba Kane \\
\hline$C(\mathrm{kPa})$ & 211 \\
$\phi\left({ }^{\circ}\right)$ & 14.9 \\
$\gamma_{h}\left(\mathrm{kN} / \mathrm{m}^{3}\right)$ & 23.5 \\
$\gamma_{d}\left(\mathrm{kN} / \mathrm{m}^{3}\right)$ & 19.4 \\
$\omega_{i}(\%)$ & 7.87 \\
$\omega_{f}(\%)$ & 20.96 \\
\hline
\end{tabular}

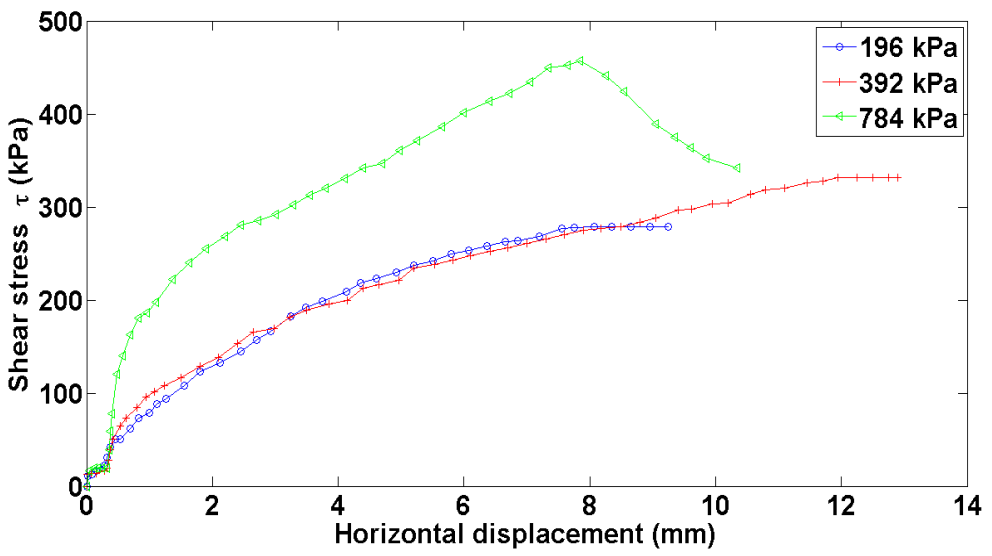

Figure 5. Evolutions of the Shear stress according to the horizontal displacement-Compacted Lateritic gravel of Keur Samba Kane.

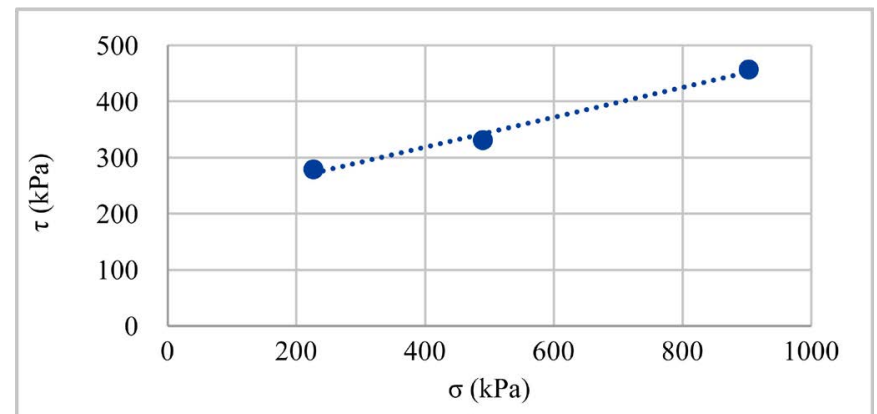

Figure 6. Intrinsic curve of the compacted lateritic gravel of Keur Samba Kane. 


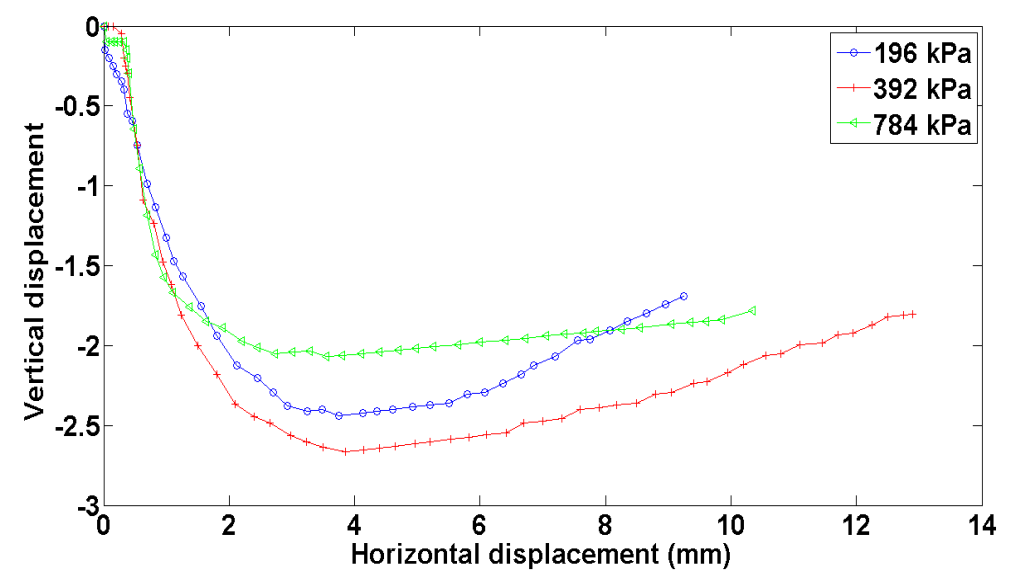

Figure 7. Evolutions of the vertical displacements according to the horizontal displacement-Compacted Lateritic gravel of Keur Samba Kane.

of the OPM [4] [5] [6]. This lateritic material of Sindia has a behaviour therefore called "ductile". For a maximal resistance of $175 \mathrm{kPa}$ during the first loading, the maximal value of this resistance to the shearing is $436 \mathrm{kPa}$ with a $784 \mathrm{kPa}$ initial normal stress. The vertical displacement versus to the horizontal displacement curve is characteristic of a contracting material [7]. This shape shows a reduction of the volume of the sample during the test. Like previously, the results of the shearing test to the shear-box of the lateritic soil of Keur Samba Kane are inserted in the "Table 3" and "Figure 5". The value of the cohesion is also high. The effect of the compaction is therefore visible with the material that is cemented itself.

For a normal initial stress of $196 \mathrm{kPa}$, the resistance to the maximal shearing is of $228 \mathrm{kPa}$, whereas for a normal initial constraint of $784 \mathrm{kPa}$, the resistance to the maximal shearing developed by the lateritic material of Keur Samba Kane in a compacted state is of $535 \mathrm{kPa}$. The curves of the vertical displacement versus the horizontal displacement all show a contracting behaviour of the material all along the test. This reduction in the volume is mainly caused by the presence of water at the time of the test that favours the settling [8].

Usually we observe for lateritic soil a dilating (resp. contracting) behaviour for low (resp. large) constraints. This transition between dilation and contraction is also observed when water content of compaction varies [9]. This is not case for our materials.

\subsection{Results of the Oedometer Tests}

The effect of the compaction is noticed well for the two samples compacted lateritic gravels at the time of the loadings to the oedometer. We do not observe an elastic slope at the beginning of the loading; the void ratio decreases after a certain level of stress "Figure 8". Before the beginning the test, we let the piston of the device react on the sample during several hours and we recorded the variation of the void ratio. Two samples exhibited a classical behaviour (one dimensional consolidation) after unloading-reloading process [10]. After these tests of 


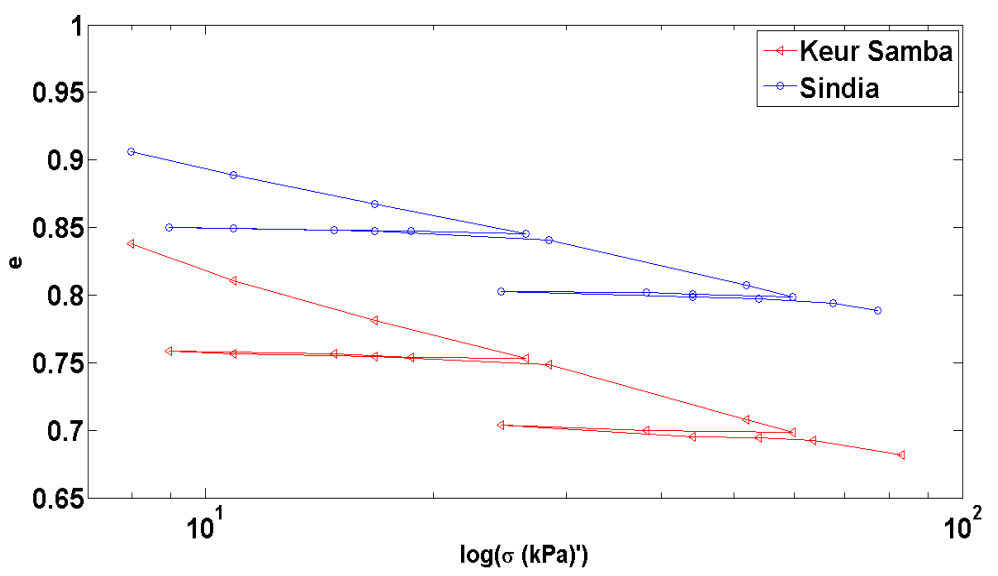

Figure 8. Curve of oedometer loading-unloading/Laterite of Sindia (blue) and of Keur Samba Kane (red).

Table 4. Characteristics of the oedometer tests Compacted lateritic gravels of Sindia and Keur Samba Kane.

\begin{tabular}{ccc}
\hline Characteristics & Sindia & Keur Samba Kane \\
\hline$e_{0}$ & 0.9 & 0.8 \\
$C c$ & 0.11 & 0.14 \\
$C s$ & 0.01 & 0.01 \\
$\sigma_{P 1}$ & 28 & 29 \\
$\sigma_{P 2}$ & 68 & 65 \\
\hline
\end{tabular}

oedometer loading-unloading, we got the following set of parameters (Table 4).

\section{Determination of the Parameters of the Cam Clay Model}

To study the mechanical behaviour of a soil by the model of Cam Clay (Table 5), we need seven parameters $\left(e_{\lambda}, \lambda, k, M, e_{0}, v\right.$ and $\left.P_{C 0}\right)$ that should be given from triaxial test.

$\lambda$ : slope of the isotropic virgin curve

$k$ s slope of the elastic curve (unloading-reloading curve)

$M$ : slope of the Critical Line State

$e_{0}$ : initial void ratio

v. Poisson coefficient

$P_{c 0}$ : pressure of pre-consolidation

$e_{\lambda}$ and $e_{k}$ : void ratio for a pressure of reference of $1 \mathrm{kPa}$.

Here, we recover these seven parameters from the shear-box and oedometer tests according to the following relations:

$$
\begin{gathered}
\lambda=C c / \ln 10 . \\
k=C s / \ln 10 . \\
P_{C 0}=\left(\sigma_{v}+2 * \sigma_{H}\right) / 3 . \\
\sigma_{v}=\sigma_{p} \text { and } \sigma_{H}=k_{0} * \sigma_{v} .
\end{gathered}
$$


Table 5. Parameters of the Modified Cam Clay Model.

\begin{tabular}{ccccccccccc}
\hline & $\lambda$ & $k$ & $M$ & $e_{0}$ & $v$ & $P_{\mathrm{c} 01}(\mathrm{kPa})$ & $P_{\mathrm{c} 02}(\mathrm{kPa})$ & $e_{\lambda}$ & $e_{k 1}$ & $e_{k 2}$ \\
\hline Sample of Sindia & 0.05 & 0.004 & 0.7 & 0.9 & 0.3 & 22.11 & 53.69 & 0.86 & 0.8 & 0.76 \\
$\begin{array}{c}\text { Sample of Keur } \\
\text { Samba Kane }\end{array}$ & 0.061 & 0.004 & 0.56 & 0.89 & 0.3 & 24.02 & 53.83 & 0.84 & 0.76 & 0.7 \\
\hline
\end{tabular}

$$
\begin{gathered}
k_{0}=1-\sin \varphi . \\
M=6 \sin \varphi /(3-\sin \varphi) .
\end{gathered}
$$

The Poisson coefficient $v$, is supposed equal to 0.3 for the two materials. The constraints matrix is given by:

$$
\sigma=\left(\begin{array}{ccc}
\sigma_{p} & - & - \\
- & \sigma_{H} & - \\
- & - & \sigma_{H}
\end{array}\right)
$$

We get the following results for the two compacted lateritic materials

\subsection{Yield Surfaces and Critical State Line (CSL): Plane $(q, p)$}

The yield surface in the plane $(p, q)$ of modified Cam Clay model is given by this expression:

$$
f=q^{2}+M^{2}\left(p^{2}-p p_{c r}\right)=0 .
$$

The Critical Line State is given by this equation:

$$
q=M p
$$

While applying these expressions to the results of our tests on the two compacted lateritic materials, we obtain the "Figure 9" and "Figure 10". In these figures of the Cam Clay's modified model, we observe yield surfaces in the shape of ellipses centred on $\mathrm{Pcr}$, the critical pressure that is the projection on the axis of the spherical pressure of the intersection between the critical state Line and the loading surface. The parameter of hardening is given by this critical pressure Pcr equal to Pc0/2. These two figures correspond to the two yield surfaces of the lateritic samples in the plane $(\mathrm{p}, \mathrm{q})$. Each of the figures watch two surfaces elasto-plastic limit with two pressures of pre-consolidation giving two critical pressures in accordance with the results of the oedometers tests.

\subsection{Isotropic Virgin Curves and Critical Line State: Plane $(e, \ln p)$}

The projection of these curves of the plane $(q, p)$ onto the plane $(e, p)$ permits us to pass to the plane $(e, \ln p)$ to see the isotropic virgin curve and the critical state line defined by the equations:

$$
\begin{gathered}
e=e_{\lambda}-\lambda \ln p, \\
e=\Gamma-\lambda \ln p,
\end{gathered}
$$

with

$$
\Gamma=e_{\lambda}-\lambda+k
$$




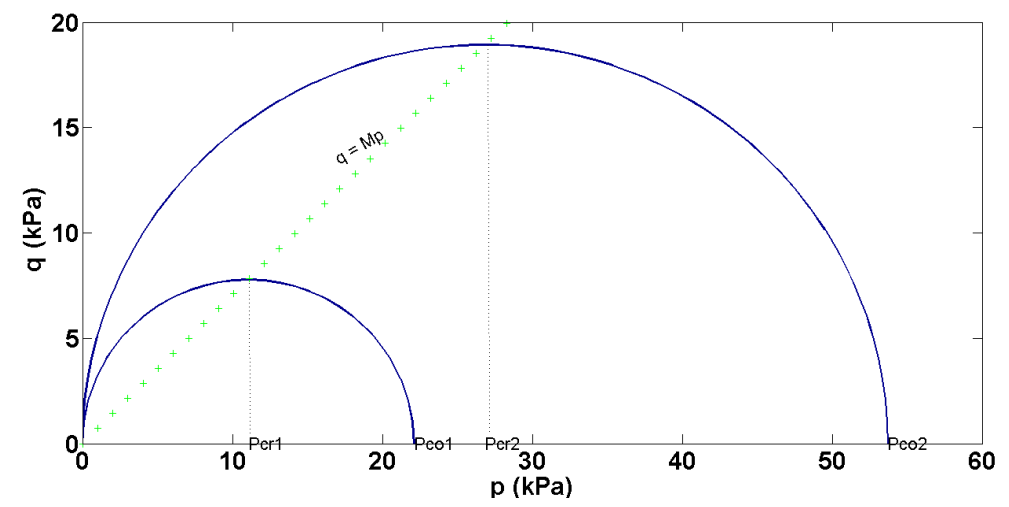

Figure 9. Yield surface and Critical Line State-Modified Cam Clay Model-Compacted lateritic gravel of Sindia.

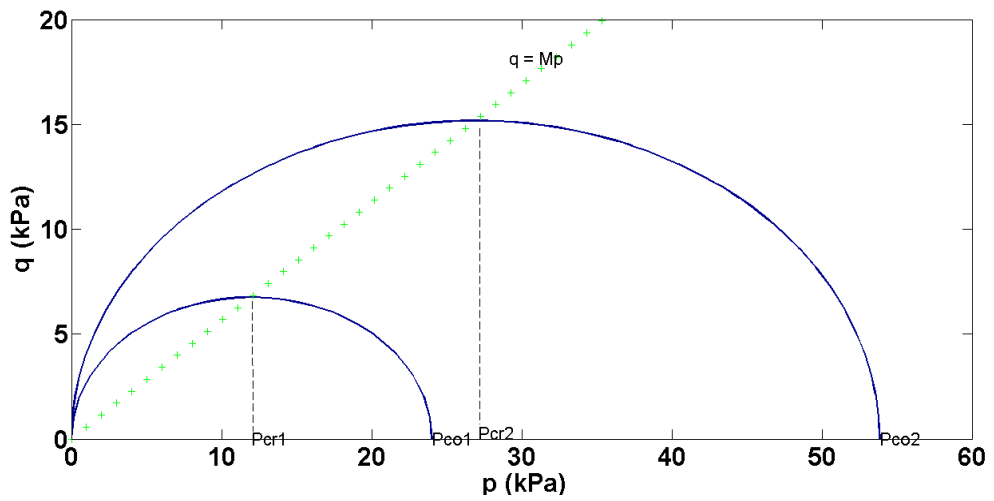

Figure 10. Yield surface and Critical Line State-Modified Cam Clay Model-Compacted lateritic gravel of Keur Samba Kane.
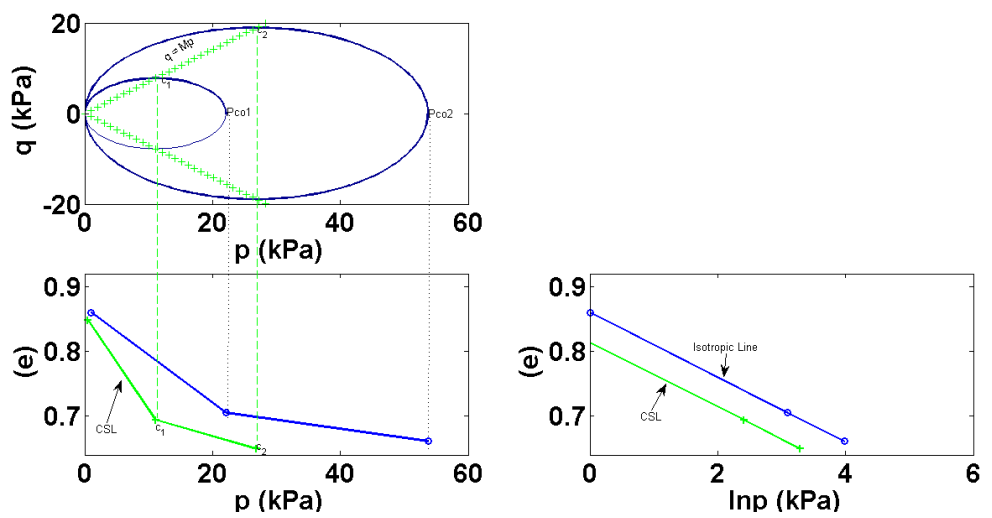

Figure 11. Projection in the plans (e, p) and (e, ln p) - Compacted lateritic gravel of Sindia.

This projection is made in the same system of axis and permits to really describe the loading path for the oedometer test.

The isotropic virgin curve (named as virgin consolidation curve) is the curve of loading that would be obtained during the isotropic triaxial test. Soil is normally consolidated all along this curve and is in a plastic state "Figure 11" and "Figure 12". 

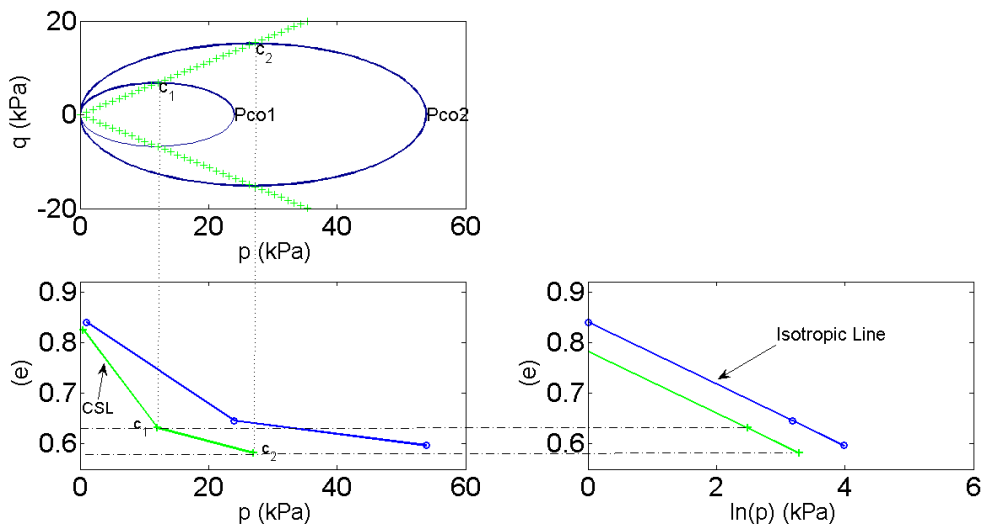

Figure 12. Projection in the plans (e, p) and (e, ln p)-Compacted lateritic gravel of Keur Samba Kane.

\section{Comparative Approach and Validation of the Results}

To validate our approach and to make a comparison between the results given by the shear-box and the oedometer tests and the results given by triaxial tests, we used the results of three samples made of compacted lateritic gravel from Senegal. This set of experimental results has been provided in [11]. We took them and tried to identify the Cam Clay model to see what will be the difference between the identification of the model using results of shear box and oedometer only or using the triaxial tests. The whole values given by the triaxial tests notably the values of spherical pressure $\mathrm{p}$ and axial deviatoric stress $\mathrm{q}$ are reported in the following "Table 6" and "Table 7" for the three studied samples. These three samples of soils are named Ndienne, Sebikhotane and Yenne mer.

\subsection{Results of the Tests of the Shear-Box and the Oedometer [11]}

The results of the consolidation tests "Table 6" give the constraints of pre-consolidation from which we calculated the pressures of pre-consolidation while considering that the materials are normally consolidated. In the same Table are given the values of the friction angle that permit to calculate the slope of the Critical State Line.

\subsection{Results from Triaxial Tests [11]}

The results of the following triaxial tests for various pressures of confinement gave the values of $p$ and $q$ "Table 7 " for every one of the three materials studied by [11]. We have used them to draw the loading surfaces corresponding to the first and to the last pressure of confinement (two surfaces) for every material.

We proceeded thus to a possible comparison with the surfaces given from consolidation tests and shear box. This triaxial tests also give the slope of the critical state line $\eta=q / p$ for the set of confinement constraints "Table 8 ".

\subsection{Identification by Modified Cam Clay Model}

We have results of shearing, oedometer and triaxial tests for three samples made 
Table 6. Shearing box and oedometer tests results.

\begin{tabular}{ccccccc}
\hline & $M$ & $\sigma p_{1}(\mathrm{kPa})$ & $\sigma p_{2}(\mathrm{kPa})$ & $P_{\mathrm{c} 01}(\mathrm{kPa})$ & $P_{\mathrm{c0} 2}(\mathrm{kPa})$ & $\Phi\left(^{\circ}\right)$ \\
\hline Ndienne & 2.05 & 210 & 2100 & 102.8 & 1028 & 50 \\
Sebikhotane & 1.9 & 210 & 2100 & 102.4 & 1076 & 47 \\
Yenne mer & 2.2 & 250 & 2200 & 116.8 & 1028 & 53 \\
\hline
\end{tabular}

Table 7. Triaxial tests results.

\begin{tabular}{ccccccc}
\hline \multicolumn{2}{c}{ Ndienne } & \multicolumn{2}{c}{ Sebikhotane } & \multicolumn{2}{c}{ Yenne } & $\sigma_{3 C}^{\prime}$ \\
\cline { 1 - 5 }$p(\mathrm{kPa})$ & $q(\mathrm{kPa})$ & $p(\mathrm{kPa})$ & $q(\mathrm{kPa})$ & $p(\mathrm{kPa})$ & $q(\mathrm{kPa})$ & $(\mathrm{kPa})$ \\
\hline 252.3 & 513.4 & 182.4 & 355.2 & 270.1 & 508.3 & 50 \\
419.4 & 819.8 & 264.1 & 465 & 328.3 & 743.5 & 100 \\
513 & 973.7 & 346.5 & 630.4 & 380.1 & 743.7 & 150 \\
532.3 & 973.4 & 519.9 & 1052 & 461.5 & 848.6 & 200 \\
953.3 & 1743 & 710.4 & 1325 & 891 & 1697 & 400 \\
1410 & 2648 & 1041 & 1788 & 1317 & 2408 & 600 \\
\hline
\end{tabular}

Table 8. Others Triaxial tests results from [11].

\begin{tabular}{cccc}
\hline & $\eta(50-150 \mathrm{kPa})$ & $\eta(200-600 \mathrm{kPa})$ & $\Phi_{c u}$ \\
\hline Sample of Ndienne & 1.77 & 1.9 & 4.7 \\
Sample of Sebikhotane & 1.66 & 1.41 & 41.9 \\
Sample of Yenne mer & 2.29 & 1.82 & 27.8 \\
\hline
\end{tabular}

of compacted lateritic gravels of Ndienne, Sebikhotane and Yenne. These results permit us verification while drawing the yield surfaces and respective CSL "Figures 13-15". That is to say, for a couple of results shear-box, oedometer test, we draw the loading surface and the CSL; for results given by the triaxial tests on the same material we draw the yield surface also and the CSL. For every material, we put the two loading surfaces on the same figure and at the same scale to compare the results.

The remark is that with the means of simple tests (shear-box and oedometer tests) we succeeded to describe the behaviour in the critical state but with less precision compared to the identification of the results given by triaxial tests.

For the samples of Ndienne and Yenne, we see that the spherical pressure is very lower (difference of $400 \mathrm{kPa}$ ) than the one of the triaxial test. It can be a consequence of the method of calculation of the pressure in the case of the oedometer test. Indeed in this case the lateral stresses is unknown and very often one uses the empirical law $k_{0}=1-\sin \varphi$ ( $k_{0}$ is the coefficient of earth pressure atrest) while considering that the materials are normally consolidated. If we observe the sample of Sebikhotane, we even see that the spherical mean pressure is larger in the case of the method of the simple tests. This sample of Sebikhotane presents the weakest angle of friction (biggest value of the empiric constant $k_{0}$ ). 

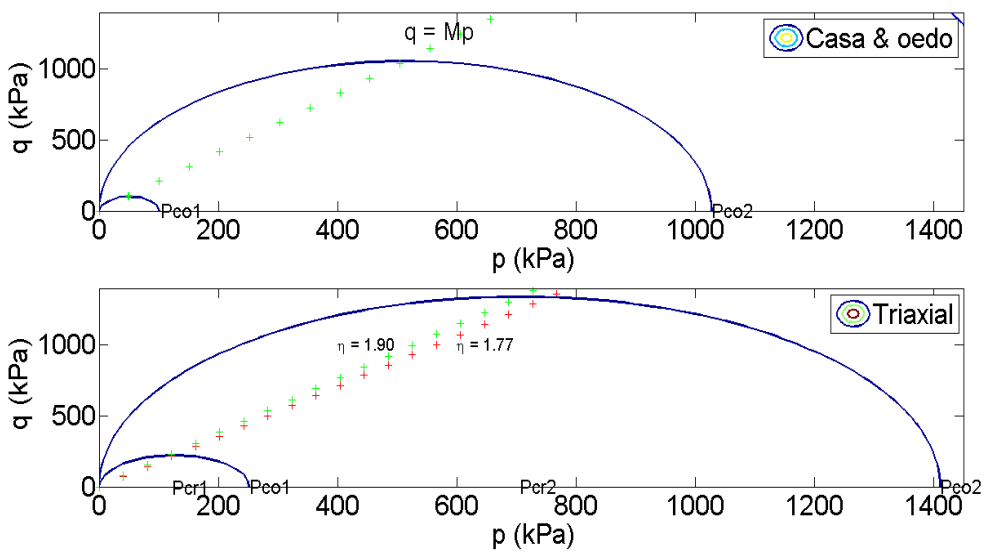

Figure 13. Yield surface and Critical Line State-Modified Cam Clay Model-Compacted lateritic gravel of NDIENNE.
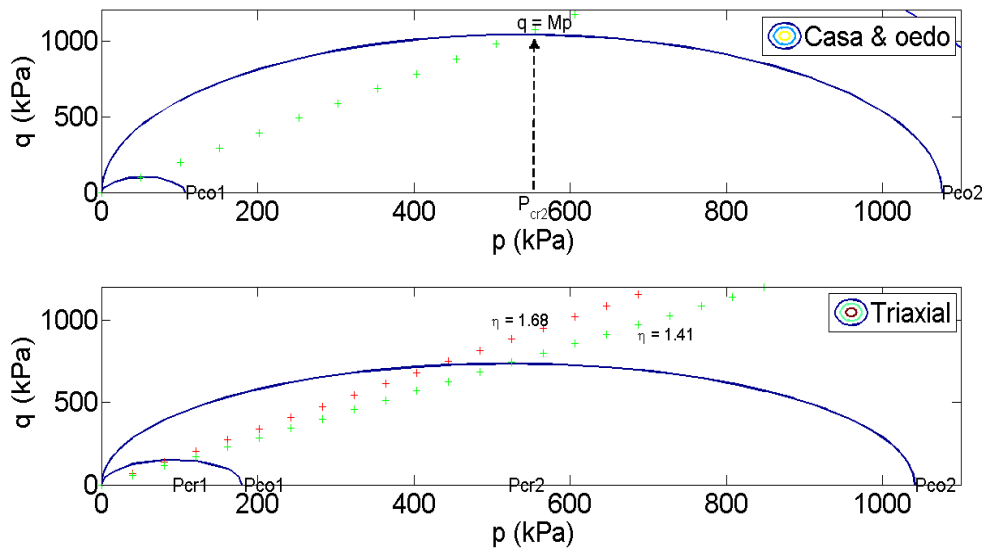

Figure 14. Yield surface and Critical Line State-Modified Cam Clay Model-Compacted lateritic gravel of SEBIKHOTANE.
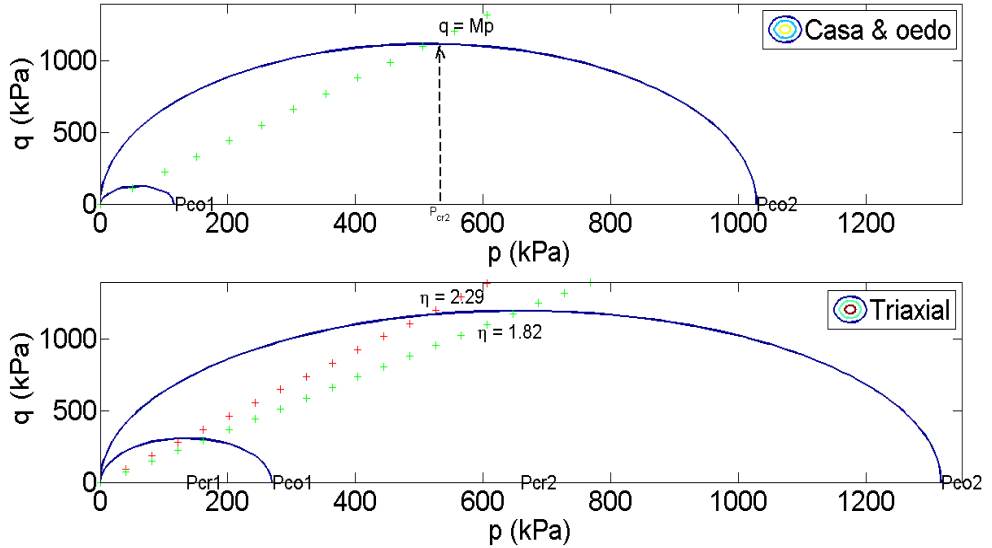

Figure 15. Yield surface and Critical Line State-Modified Cam Clay Model-Compacted lateritic gravel of YENNE.

\section{Acknowledgements}

I deeply thank all researchers from the Laboratory of Mechanics and Modelling of the UFR Sciences de l'Ingénieur of the University of Thiès and the Laboratory 
of D'Alembert of the University of Pierre et Marie Curie-Paris.

\section{References}

[1] Roscoe, K.H., Schofield A.N. and Wroth C.P. (1958) On the Yielding of Soils. Géotechnique, 8, 22-53. http://doi.org/10.1680/geot.1958.8.1.22

[2] Schofield, A. and Wroth, P. (1968) Critical State Soil Mechanics. Lecturers in Engineering at Cambridge University. http://www.civ.eng.cam.ac.uk/geotech_new/publications/schofield8wroth81968.pdf

[3] Atkinson, J.H., Bransby P.L. (1978) The Mechanics of Soil: An Introduction to Critical State Soil Mechanics. McGraw-Hill Book Company (UK) Limited, Maidenhead, Berkshire, England, ISBN 070841357.

[4] Fall, M., Tisot, J.P. and Cisse, I.K. (1995) Stress-Strain Behaviour of Three Compacted Lateritic Gravels from Western Senegal Using the Box Machine. Bulletin of International Association of Engineering Geology, 52, 59-73.

[5] Sikali, F. (1985) Détermination d'un modèle rhéologique pour une latérite compactée par des essais simples de laboratoire. Journées Univ. G. C. "Méc. Sols Appl." INSA Lyon (22-30 Oct. 1985).

[6] Fall, M., Tisot, J.P. and Cisse, I.K. (1995) Comportement mécanique à l'appareil de cisaillement de Casagrande de trois graveleux latéritiques provenant du Sénégal occidental. BULLETIN de l'Association Internationale de GÉOLOGIE DE L'INGÉNIEUR Paris, Octobre 1995, Vol. 52, 59-73.

[7] Berthaud, Y., De Buhan, P. and Schmitt, N. (2013) Aide-mémoire de mécanique des sols-Dunod Ed. $2^{\mathrm{e}}$ édition, Dunod Ed./L’Usine Nouvelle, collection Aide-mémoire de l'ingénieur, $320 \mathrm{p}$.

[8] Baldovin, G. (1969) The Shear Strength of Lateritic Soils. Proc. Of the Spec. Session of Eng. Prop. Of lateritic Soils, Seventh Int. Conf. on Soil Mech. and Found. Eng., 1, 129-142.

[9] Fall, M., Tisot, J.P. and Cisse, I.K. (1994) Proposition pour une classification des graveleux latéritiques (application au cas du Sénégal). Bulletin of International Association of Engineering Geology, 50, 17. https://doi.org/10.1007/BF02594953

[10] Ndiaye, C., Fall, M., Ndiaye, M., Sangare, D. and Tall, A. (2014) A Review and Update of Analytical and Numerical Solutions of the Terzaghi One-Dimensional Consolidation Equation. Open Journal of Civil Engineering, 4, 274-284.

[11] Fall, M. (1993) Identification et caractérisation mécanique de graveleux latéritiques du Sénégal: Application au domaine routier. Thèse de Doctorat de l'I.N.P.L (Institut National Poly-technique de Lorraine/France) en Géni Civil, 240 p. 